found in many cases of pseudotumour whatever the cause and consequently is of little help, ${ }^{12}$ but adequate temporal artery biopsy may help in diagnosis and should also be performed. Though the condition may remit spontaneously, in temporal arteritis delay in diagnosis may allow further irreversible arteritic complications to occur. Corticosteroids in adequate dosage produce dramatic symptomatic benefit and objective improvement follows within a week, so that it may be clinically prudent to treat elderly patients with a trial of corticosteroids rather than resort to prolonged investigation or transfer to a specialized centre for further procedures.

I tentatively suggest that many of the idiopathic granulomatous pseudotumours of the orbit in elderly patients responding to corticosteroids are in reality caused either by temporal arteritis or Wegener's granulomatosis, possibly in the "limited" form described by Carrington and Liebow. ${ }^{3}$ After a successful trial of corticosteroids the patient should receive prolonged follow-up to prevent recurrence of the parent disease when corticosteroids are reduced or discontinued. -I am, etc.

Manchester Royal Infirmary,

PhILIP GIBBS Manchester

1 Jackson, H., British foumal of Ophthalmology, 1958, 42, 212 .

Coop, M. E., British foumal of Ophthalmology, Carrington, $C$.

A. American

fournal of Medicine, 1966, 41, 497 .

\section{Hypothermia, Thrombosis, and Acute} Pancreatitis

SIR,-The report by Drs. E. P. Savides and B. I. Hoffbrand ( $30 \mathrm{March}$, p. 614 ) of a fatal case of hypothermia, in which acute pancreatitis was found in association with thrombosis in the upper superior pancreaticoduodenal vein and its intrapancreatic branches, merits comment.

First, though visceral thrombosis and infarction seem to be complications of hypothermia rather than of pancreatitis it is unlikely that the acute pancreatitis so commonly found in patients with accidental hypothermia can be explained on this basis. Pancreatitic venous thrombosis in association with acute pancreatitis has not been mentioned in any of the major series of cases of accidental hypothermia so far published. ${ }^{2}$ It remains ooncivable, however, that even in the absence of such thrombosis ischaemia may still contribute to the pancreatitis. $^{3}$

Second, the presenting clinical features of generalized and rebound tenderness of the abdomen are not characteristic of the acute pancreatitis in those with accidental hypothermia. ${ }^{2}$ In the last few years I have extensively studied more than 100 patients with accidental hypothermia and I have found the signs of an acute abdomen only in those patients in whom one of two associated conditions was present: (1) perforation of an acute gastric or duodenal ulcer with secondary peritonitis; (2) mesenteric vascular occlusion with gangrene of part of the small bowel.

None of my patients in whom pancreatitis was confirmed at necropsy had shown signs of an acute abdomen. It follows therefore that in the case described by Drs. Savides and Hoffibrand an alternative explanation for their findings is that the hypothermia may simply have been an epiphenomenon in a patient originally suffering from acute pancreatitis, with the venous thrombosis being a later complication of the hypothermia. Like others, ${ }^{4}$ I have found that in the elderly patient with accidental hypothermia the hypothermia is usually a secondary phenomenon in someone suffering from a primary serious underlying illness, the latter often dominating the clinical picture and determining the main need for any therapy. None the less, now that Drs. Savides and Hoffbrand have drawn attention to their finding it will be interesting to see how often it is found by others.-I am, etc

DEREK MACLEAN

Department of Medicine

Ninewells Hospital and Medical School, Dundee

1 Duguid, H., Simpson, R. G., and Stowers, J. M., Lancet, 1961, 2, 1213.

Mant, A. K., British fournal of Hospital Medicine, 1969, 2, 1095.

Maclean, D., Murison, J., and Griffiths, P. D., British Medical fournal, 1973, 4, 757.

Weyman, A. E., Greenbaum, D. M., and Grace, W. J., American fournal of Medicine, 1974, 56,

SIR,-We were interested to read the account by Drs. E. P. Savides and B. I. Hoffbrand of a case of acute pancreatitis associated with hypothermia (30 March, p. 614). It appeared from their review of the literature that acute pancreatitis, as well as other common complications of hypothermia, may have been precipitated by circulatory stasis. The incidence of thrombosis in various vessels has been found to be very high at necropsies following hypothermic deaths.

A possible explanation of this finding may be the increase in blood viscosity with a fall in temperature. The acoompanying figure shows the change in viscosity of the

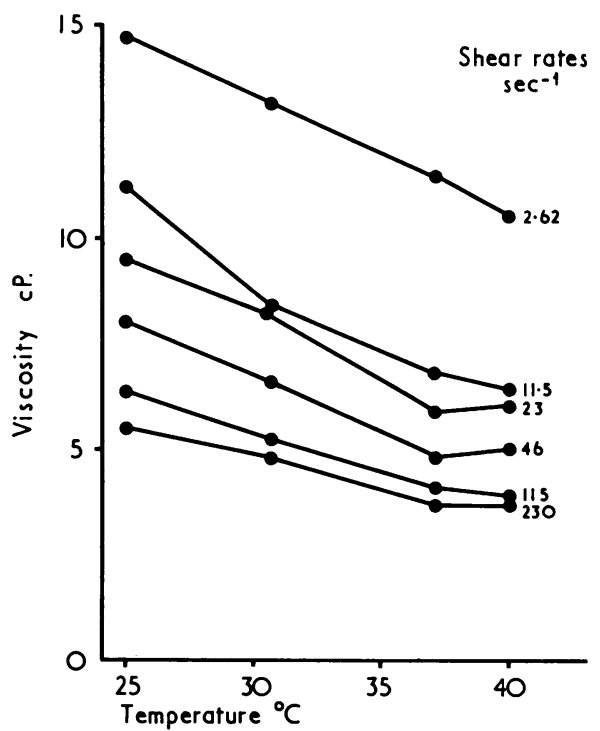

same sample of whole blood at different temperatures -ranging from $25^{\circ} \mathrm{C}$ to $40^{\circ} \mathrm{C}$. The viscosities were determined at a number of shear rates, from $2.62 \mathrm{sec}^{-1}$ to $230 \mathrm{sec}^{-1}$. The result illustrates the significant effect of temperature on viscosity.

A patient with a rectal temperature of $30.5^{\circ} \mathrm{C}$ such as the one described by Drs. Savides and Hoffibrand would have had a blood viscosity at most shear rates $25-40 \%$ higher than that at normal body tempera- ture. This would have resulted in a decrease in blood flow sufficient to increase significantly the chances of thrombosis.-We are, etc.

E. HOARE

Manchester Royal Infirmary, Mancheste

J. C. Postlethwaite

Royal College of Surgeons, London W.C.2

JOHN DORMANDY

St. George's and St. James's Hospitals, London

\section{Adverse Reactions to Intra-amniotic} Urea and Prostaglandin

SIR,-The adverse reaction at the time of an intra-amniotic injection of urea and prostaglandins reported by $\mathrm{Mr}$. A. H. Ross and Mr. W. L. Whitehouse (30 March, p. 642) is not a feature that we have noticed in 200 patients treated by this method, using a fixed dose of $80 \mathrm{~g}$ of urea and variable doses of prostaglandins $\mathrm{E}_{2}$ and $\mathrm{F}_{2} \alpha$.

The symptoms described strongly suggest that a relatively large dose of prostaglandin had rapidly reached the systemic circulation. Such an occurrence is possible if the needle or cannula used becomes misplaced outside the gestation sac, and because of this we advise that a cannula with side drainage holes be used and that care be taken to ensure that there is free flow-back of liquor into the syringe throughout the injection procedure. If not, we refrain from injecting the agents. We also prefer to wait until after 16 weeks because the method is technically easier, there being less likelihood of the amniotic sac being drained following aspiration of the advised $100 \mathrm{ml}$ of liquor and of resultant trauma to the placenta, even with the routine use of ultrasound localization. We feel that the aspiration of some liquor is required since the urea solution administered $(80 \mathrm{~g}$ of urea added to $80 \mathrm{ml}$ of Hartmann's solution makes approximately $140 \mathrm{ml}$ ) may rarely lead to over-distension of the sac with loss of the abortifacient agents and subsequent uterine activity. Our main oncern about possible complications occurring with this technique is that of excessive uterine activity resulting in cervical injuries as recently described (4 May, p. 271), and has led to the evaluation of using low doses of prostaglandin-for example, $2.5 \mathrm{mg}$ of prostaglandin $\mathrm{E}_{2 .}-\mathrm{We}$ are, etc.

Institute of Obstetrics and Gynaecology,

IAN CRAFT Chelsea Hospital for Women, London S.W.3

PETER BOWEN-SIMPKINS Department of Qbstetrics and Gynaecology, Middlesex Hospital,

\section{Ideal Consultation}

SIR,-In the course of his generous review of Six Minutes for the Patient (6 April, p. 65), Dr. Andrew Smith makes a statement which, unqualified, might appear to perpetuate the mind-body dichotomy, which I am sure was not his intention. He writes, "the patient with tonsillitis needs penioillin, not insight." Without wanting to split semantic hairs might I suggest that it is the tonsillitis which needs penicillin, and that the patient-as-a-person may stand in need of something more? The trouble is that we simply do not know how to assess this need accurately, our present methods being relatively primitive. As Dr. Smith says, the 
Balint research group tried to examine this intuitive process scientifically.

Perhaps, though, it is not the patient who needs insight, but the doctor. Insight and discretion, so that each interventionwhether chemotherapeutic or psychotherapeutic-is right and relevant for the patient. -I am, etc.,

J. S. NORRELL

London N.7

\section{Antioestrogens in Treatment of Breast} Cancer

SiR,-The paper by Drs. H. J. G. Bloom and Evelyn Boesen (6 April, p. 7) on the treatment of advanced breast cancer by nafoxidine calls for comment on the mechanism postulated for tumour inhibition by this agent. The authors noted tumour regression in 11 out of 26 patients in the group who were within five years after the menopause (a total figure which I have deduced by including the castrated patients also). If nafoxidine acts by depriving tumour tissue of oestrogen (as they suggest) such a high response rate is remarkable in an age group which responds very rarely to castration, bilateral adrenalectomy, or hypophyseal ablation. All of these are methods whose major action is thought to be by oestrogen deprivation of tumour tissue.

In fact, the therapeutic effect of nafoxidine in postmenopausal women with breast cancer is just as likely to be by an oestrogenic action as by an antioestrogenic action. ${ }^{12} \mathrm{~A}$ reflection of the former effect is the keratinization noted by Drs. Bloom and Boesen in the vaginal smears of their patients receiving nafoxidine. There are, however, two major objections to the suggestion of an oestrogenic action for agents such as nafoxidine on breast cancer. Firstly, the effective dosage of antioestrogens in breast cancer is of the same order as that used for gynaecological disorders, whereas massive dosage of oestrogens is required for tumour regression. ${ }^{1}$ Secondly, oestrogen therapy very rarely causes regression of breast cancer in the five years after the menopause, and may indeed be contraindicated because of the danger of exacerbating the disease in this age group. ${ }^{3}$

Both of these objections can be explained away by the recent observation of L'Hermite $^{2}$ that whereas oestrogen stimulates prolactin release from the human pituitary nafoxidine does not. In the case of hormone-sensitive rat mammary carcinoma tumour regression requires very high dosage of oestrogen in order to oppose at the target the mitosis-stimulating effect of the prolactin released by oestrogen from the pituitary. ${ }^{4}$ If we accept the role of prolactin in stimulating breast cancer in the human also it explains why antioestrogens can cause tumour regression at a much lower dosage than that of oestrogens and at the same time do not involve the danger of exacerbating tumour activity in the early postmenopausal age group. Antioestrogens do not stimulate prolactin release from the pituitary gland. However, unlike L'Hermite, ${ }^{2}$ I would not necessarily expect a greater effect on breast cancer from antioestrogens than from oestrogens because of this.-I am, etc.,

Basil A. Stoll 1 Terenius, L., in Mammary Cancer and NeuroL'Hermite, M., et al., British Medical fournal, toll, B. A., ed., Endocrine Therapy of Malignant Disease, p. 155. Philadelphia and London,
Saunders, 1972.

t Meites, J., Cassell, E., and Clark, J., Proceedings of the Society for Experimental Biology and Medicine, 1971, 137, 1225.

\section{Place of the Occupational Therapist}

SIR,-The hospital services at present are suffering from a catastrophic loss of occupational therapists, who are being enticed by local authorities at a $50 \%$ increase in salary as social workers classed as "advisers in aids to the disabled." These occupational therapists are no longer utilizing the skills which they have so painfully acquired. They are, on the whole, under-employed. Their sole function appears to be to request the building of aids for the disabled by usually nonexistent joiners.

The loss of occupational therapists in large numbers from hospital services is having a significant effect on restoration to independence and return to home, particularly of the elderly, with resultant blocking of expensive hospital beds. The correct place for the occupational therapist is in multidisciplinary hospital rehabilitation teams. Her main function should be to help in the early return to community life of the sick and helpless patient.

Before the implementation of the Seebohm Report $^{1}$ it was quite common for the hospital occupational therapist to advise on aids for the disabled in the home or in collaboration with one or two local authority occupational therapists, who were all that was really needed in this sphere. The wastage of financial resources by local authorities on developing occupational therapy services to the detriment of hospital service recruitment is retrograde and should be countermanded by central management. At the same time the improvement of salary scales of hospital accupational therapists and physiotherapists should be accelerated.-I am, etc.,

W. FINE

Newsham General Hospital, 1 Report of the Committee on Local Authority and
Allied Personal Services. London, H.M.S.O.,
1968.

\section{Consultant Crisis}

SIR,-Senior hospital medical staff are rarely seen to be united or militant, but the profound dissatisfaction with the consultant's contract, remuneration, and terms of service has produced this phenomenon in our area.

A Senior Medical Staff Committee has just been formed, since the advent of Cogwheel had done away with any previous medical forum at which consultants and medical assistants could meet together to discuss conditions of terms of service in the National Health Service. We feel that a state of crisis has been reached and that there is a decline in the standards of hospital medicine which we think will be progressive. This decline we attribute to the inability of the hospital service to attract graduates suitable for specialist training because of poor prospects. Young graduates are being attracted to general practice or to emigration
(440 U.K. graduates emigrated in 1973). There are some 11,000 consultants in this country and more than 1,000 unfilled posts. It was previously agreed that our greatly increasing work load and relative decrease in remuneration had led to the low morale and marked decline in hospital standards and that the dangers of the state of crisis that had been reached had not been appreciated by the Department of Health and Social Security. It is clear from the devious evasions of the Department in its negotiations with the B.M.A. that it is their hope that our degree of job satisfaction will prevent us from being too militant. It follows therefore that negotiations conducted along the lines previously used by the negotiating subcommittee are doomed to failure. We have agreed to strengthen the hand of our negotiators by instituting sanctions in this area if necessary. Sanctions should initially be non-clinical, such as total withdrawal from medical executive committees, management teams, etc. Within a short time, if these sanctions are not sufficient, the option for sterner measures should be kept open. It should be borne in mind that the average consultant is working beyond his normal session times and that the D.H.S.S. is trading on our goodwill.

Our decision has been forwarded to our Regional Committee for Hospital Medical Services, and we would earnestly request that senior medical staff in other areas hold similar meetings to discuss the present crisis and to inform their regional committee of the outcome.-We are, etc.,

\section{H. TEASDALE \\ I. G. SCHRAIBMAN \\ I. B. MUNRO
G. F. W. HOSSACR \\ J. LENDRUM \\ P. PRASER \\ L. D. DAlal}

The Infirmary,

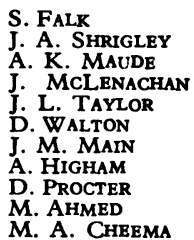

Rochdale

\section{G.P.s and Family Planning}

SIR, - I have today paid the sum of $£ 4.60$ to my veterinary surgeon in respect of family planning for my bitch. At last we have the standard for a fee which should be paid for family planning consultations in general practice.-I am, etc.,

Chelmsford, Essex

J. TUdor PeMbletoN

\section{G.P.s' Pay}

SIR,-May we record our absolute support for the views expressed by Drs. D. W. L. Smith and N. C. Varey (11 May, p. 336). We are convinced that if no satisfactory Review Body report is forthcoming the issue of resignation from the N.H.S. must be reconsidered.

We feel that while G.P. expenses and general inflation increase incomes have been static. The work load is increasing, as are the demands of the N.H.S. Let the profession this time stand united and demand their just rewards.-We are, etc.,

J. V. THOMAS
B. L. ROBINSON
J. MCCARTHY
Langley, Bucks

